GRT repair was 76 letters, improving to 80 letters after a total of seven patients underwent cataract surgery following a median interval of 6 months (range 4-21 months). This was significantly better than the baseline VA $(p<0.001)$. The prevalence of visual loss $\geq 10$ letters at 3 months was 4 (16\%), which improved to baseline or better in all four following subsequent cataract surgery. Redetachment (maculaon) occurred in two out of 25 patients (8\%) following removal of PFCL due to smaller missed breaks. Both were successfully repaired with cryotherapy and gas tamponade.

In keeping with other reports [5-7], short-term use of post-operative PFCL in this study was associated with good primary and final anatomical success rates. Notably, in contrast to the reported high rate of vision loss after ROSO in the same patient group i.e. macula-on detachments $[1,8$, 9] there were no unexplained visual acuity losses in our series. PFCL may thus mitigate the high incidence of unexplained vision loss after ROSO in those eyes where a good visual outcome is expected. Vitreoretinal surgeons should consider PFCL as an alternative to $\mathrm{SiO}$ or gas as a post-operative tamponade agent in macula-on GRT repair.

Acknowledgements Additional members of the Vitreoretinal Unit of the Royal Victorian Eye and Ear Hospital who performed surgery on these cases: Drs M F McCombe, D Chiu, R Dawkins, E Roufail, J B Clark and D Fabinyi.

Ethical approval The study protocol was approved by the Royal Victorian Eye and Ear Human Research Ethics Committee (HREC approval $07 / 759 \mathrm{H}$ ) and all procedures were conducted in accordance with the tenets of the Declaration of Helsinki 7th revision.

\section{Compliance with ethical standards}

Conflict of interest The authors declare that they have no conflict of interest.

\section{References}

1. Moya R, Chandra A, Banerjee PJ, Tsouris D, Ahmad N, Charteris DG. The incidence of unexplained visual loss following removal of silicone oil. Eye. 2015;29:1477-82.

2. Roca JA, Wu L, Berrocal M, Rodriguez F, Alezzandrini A, Alvira $\mathrm{G}$, et al. Un-explained visual loss following silicone oil removal: results of the Pan American Collaborative Retina Study (PACORES) Group. Int J Retin Vitr. 2017;3:26.

3. Bottoni F, Bailo G, Arpa P, Prussiani A, Monticelli M, de Molfetta V. Management of giant retinal tears using perfluorodecalin as a postoperative short-term vitreoretinal tamponade: a long-term follow-up study. Ophthalmic Surg. 1994;25:365-73.

4. Campbell WG, McCombe MF. The management of giant retinal tears with short-term tamponade with perfluoro-N-octane and transscleral diode photocoagulation. 29th Annual Scientific Meeting of the Royal Australian and New Zealand College of Ophthalmologists, Sydney; 1997

5. Sirimaharaj M, Balachandran C, Chan WC, Hunyor AP, Chang AA, Gregory-Roberts J, et al. Vitrectomy with short term postoperative tamponade using perfluorocarbon liquid for giant retinal tears. Br J Ophthalmol. 2005;89:1176-9.

6. Randolph JC, Diaz RI, Sigler EJ, Calzada JI, Charles S. 25-gauge pars plana vitrectomy with medium-term postoperative perfluoro-noctane for the repair of giant retinal tears. Graefes Arch Clin Exp Ophthalmol. 2016;254:253-7.

7. Eiger-Moscovich M, Gershoni A, Axer-Siegel R, Weinberger D, Ehrlich R. Short-term vitreoretinal tamponade with heavy liquid following surgery for giant retinal tear. Curr Eye Res. 2017;42:1074-8.

8. Tode J, Purtskhvanidze K, Oppermann T, Hillenkamp J, Treumer F, Roider J. Vision loss under silicone oil tamponade. Graefes Arch Clin Exp Ophthalmol. 2016;254(8): $1465-71$.

9. Christensen UC, la Cour M. Visual loss after use of intraocular silicone oil associated with thinning of inner retinal layers. Acta Ophthalmol. 2011;90:733-7.

\title{
Trainee confidence managing ocular trauma
}

\author{
Amy-lee Shirodkar ${ }^{1} \cdot$ Damien CM Yeo $\mathbb{D}^{1} \cdot$ Mr. Gary Shuttleworth ${ }^{2}$
}

Received: 29 November 2018 / Accepted: 7 December 2018 / Published online: 7 January 2019

(c) The Royal College of Ophthalmologists 2019

\author{
$\triangle$ Amy-lee Shirodkar \\ a-1.s@gmx.com \\ Cardiff Eye unit, UHW, Cardiff, UK \\ 2 Ophthalmology, Singleton Hospital, Swansea, UK
}

Morris et al. [1], showed a reduction in serious cases of ocular trauma between 1992 and 2009 by fourfold and there is a real risk that repairing ocular trauma is now so 
infrequently performed that a large portion of the ophthalmic community has insufficient skills to carry out repeatabily safe and secure repairs. As part of training, an Ophthalmology trainee is expected to be able to perform a minimum of two surgical repairs of ocular and adnexal tissues in 7 years. We surveyed a cross-section of Ophthalmic trainees, of all training grades, for their perceived levels of confidence and experience managing ocular trauma. Totally, $96 \%$ of Welsh trainees completed the survey, over a 12 month period they were exposed to 43 cases of ocular trauma repairs, an average of 2 per trainee, ranging from none to 6 . The infrequency and unpredictability mean that experiences may be difficult to obtain and limited by the time, with $41 \%$ of trainees believing they would not achieve two assessments. Overall, $78 \%$ of trainees reported negative confidence when performing surgery for cases of ocular trauma, which were associated with an average of one case or less a year and not having completed cornea or oculoplastics training placements. Trainees felt if they were encouraged to perform transferable steps, for example a trainee would learn the skills to repair conjunctival lacerations by suturing a conjunctival graft during pterygium surgery, their confidence would increase. Despite attending simulation events and courses, in the trainee's mind there is still no substitute for personal experience as interestingly no significant differences in perceived confidence were apparent between trainees who had attended trauma courses to those that had not.

These results will be of interest both to those constructing curricula and those delivering training of our future Ophthalmologists. With the shift towards safer 'in-hours' operating, luck of exposure and changes to working hours, priority should be given with short notice cancellation for a trainee's routine clinical activity. Our survey is a warning that if we are to continue providing safe out of hours services, teaching resources require proper assessment and development to meet these needs.

\section{Compliance with ethical standards}

Conflict of interest The authors declare that they have no conflict of interest.

Publisher's note: Springer Nature remains neutral with regard to jurisdictional claims in published maps and institutional affiliations.

\section{References}

1. Morris DS, Willis S, et al. The incidence of serious eye injury in Scotland: a prospective study. Eye. 2014;28:34-40. 